\title{
Enhancing Reductive Cleavage of Aromatic Carboxamides
}

XXXX

Vol. 0, No. 0

$\mathbf{A}-\mathbf{C}$

\author{
Ulf Ragnarsson, ${ }^{*}$ Leif Grehn, Hernani L. S. Maia, ${ }^{\dagger}$ and Luis S. Monteiro ${ }^{\dagger}$ \\ Department of Biochemistry, University of Uppsala, Biomedical Center, PO Box 576, \\ SE-751 23 Uppsala, Sweden, and Departamento de Quimica, Universidade do Minho, \\ Gualtar, P-4700-320 Braga, Portugal
}

urbki@bmc.uu.se

Received April 16, 2001

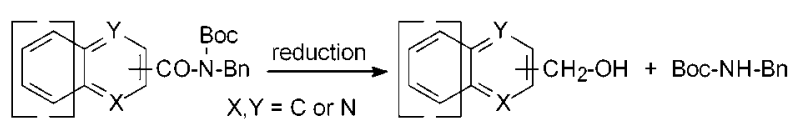

A set of aromatic and especially heteroaromatic $\mathrm{N}$-benzyl carboxamides, derived from naphthalene, pyridine, pyrazine, and quinoline, and the corresponding tert-butyl acylcarbamates have been synthesized and studied by cyclic voltammetry with respect to facilitated reduction. The latter undergo regiospecific cleavage of their $\mathrm{C}(0)-\mathrm{N}$ bonds under very mild reductive conditions with formation of Boc-protected (benzyl)amine in most cases in nearly quantitative yields. Examples of preparative cleavage by controlled potential electrolysis, activated aluminum, and $\mathrm{NaBH}_{4}$ are given.

Among protected derivatives of amines, simple amides are exceptionally stable to acidic and basic hydrolysis and they are therefore often hydrolyzed by brute force by heating with strongly acidic or basic solutions. ${ }^{1}$ Aromatic amides such as benzamides are particularly stable toward these reagents but can be cleaved by cathodic reduction to give the amines in respectable yields with concomitant formation of the corresponding alcohols. ${ }^{2}$ The potential required for such cleavages is quite negative, but we have found that it can be increased moderately by $N$-Boc substitution. ${ }^{3}$ Such conversion from amide to tert-butyl acylcarbamate can be easily accomplished by $\mathrm{Boc}_{2} \mathrm{O} / \mathrm{DMAP}{ }^{4}$

With the aim to facilitate mild reductive cleavage of amides, a number of $N$-benzyl amides $1(\mathrm{Ar}=1$ - and 2-naphthyl; 2-, 3-, and 4-pyridyl; pyrazyl; and 2-quinolyl) have been prepared and subsequently converted to the

$\dagger$ Universidade do Minho.

(1) Greene, T. W.; Wuts, P. G. M. Protective Groups in Organic Synthesis, 3rd ed.; Wiley-Interscience: New York, 1999; pp 550-564.

(2) Horner, L.; Neumann, H. Chem. Ber. 1965, 98, 3462 and references therein.

(3) (a) Grehn, L.; Gunnarsson, K.; Maia, H. L. S.; Montenegro, M. I.; Pedro, L.; Ragnarsson, U. J. Chem. Res. 1988, (S) 399; (M) 3081. (b) Maia, H. L. S.; Monteiro, L. S.; Degerbeck, F.; Grehn, L.; Ragnarsson, U. J. Chem. Soc., Perkin Trans. 2 1993, 495

(4) (a) Flynn, D. L.; Zelle, R. E.; Grieco, P. A. J. Org. Chem. 1983, 48, 2424. (b) Ragnarsson, U.; Grehn, L. Acc. Chem. Res. 1998, 31, 494. corresponding tert-butyl acylcarbamates $\mathbf{2}$ according to the following scheme:

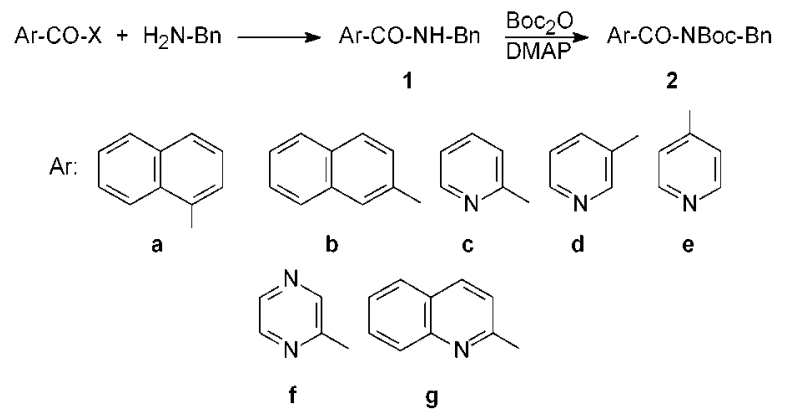

The common feature of the acyl substituents is that the corresponding (hetero)arenes are more easily reduced than benzene. ${ }^{5}$ Compounds $\mathbf{1}$ and $\mathbf{2}$ have initially been studied by cyclic voltammetry $(\mathrm{CV})$, and their activation potentials have been determined. These results are summarized in Table 1.

Entries 1 and 3 demonstrate that replacement of phenyl by 1- or 2-naphthyl has a similar effect on the redox potential

(5) (a) Gerson, F.; Ohya-Nishiguchi, H.; Wydler, C. Angew. Chem. 1976, 88, 617; Angew. Chem., Int. Ed. Engl. 1976, 15, 552. (b) Parker, V. D. J. Am. Chem. Soc. 1976, 98, 98. (c) Tabner, B. J.; Yandle, J. R. J. Chem. Soc. A 1968, 381. (d) Wiberg, K. B.; Lewis, T. P. J. Am. Chem. Soc. 1970, $92,7154$. 
Table 1. Substituted Amides/tert-Butyl Acylcarbamates Prepared and Studied by Cyclic Voltammetry

\begin{tabular}{|c|c|c|c|}
\hline entry & amide $\mathbf{1}$ /carbamate $\mathbf{2}^{\mathrm{a}}$ & $-E_{p} N^{b}$ & $E_{P 2}-E_{P 1} N$ \\
\hline 1 & N-benzyl-1-naphthamide $\mathbf{1 a}$ & 2.11 & 0.30 \\
\hline \multirow[t]{2}{*}{2} & N-benzyl-N-Boc-1-naphthamide $\mathbf{2 a}$ & 1.81 & \\
\hline & 1-naphthamide & 2.23 & \\
\hline 3 & N-benzyl-2-naphthamide $\mathbf{l b}$ & 2.21 & 0.32 \\
\hline \multirow[t]{4}{*}{4} & N-benzyl-N-Boc-2-naphthamide $\mathbf{2 b}$ & 1.89 & \\
\hline & 2-naphthamide & 2.27 & \\
\hline & $\mathrm{N}$-benzyl benzamide & $2.52^{3 b}$ & \\
\hline & benzamide & 2.55 & \\
\hline 5 & $\mathrm{~N}$-benzyl-2-pyridinecarboxamide $\mathbf{1 c}$ & 2.09 & 0.35 \\
\hline \multirow[t]{2}{*}{6} & $\begin{array}{l}\mathrm{N} \text {-benzyl-N-Boc-2-pyridine- } \\
\text { carboxamide } 2 \mathrm{c}\end{array}$ & 1.74 & \\
\hline & 2-pyridinecarboxamide & 2.11 & \\
\hline 7 & $\mathrm{~N}$-benzyl-3-pyridinecarboxamide $\mathbf{1 d}$ & 2.29 & 0.50 \\
\hline \multirow[t]{2}{*}{8} & $\begin{array}{l}\text { N-benzyl-N-Boc-3-pyridine- } \\
\text { carboxamide } \mathbf{2 d}\end{array}$ & 1.79 & \\
\hline & 3-pyridinecarboxamide & 2.31 & \\
\hline 9 & $\mathrm{~N}$-benzyl-4-pyridinecarboxamide $\mathbf{l e}$ & 2.05 & 0.34 \\
\hline \multirow[t]{2}{*}{10} & $\begin{array}{l}\mathrm{N} \text {-benzyl-N-Boc-4-pyridine- } \\
\text { carboxamide } \mathbf{2 e}\end{array}$ & 1.71 & \\
\hline & 4-pyridinecarboxamide & 2.03 & \\
\hline 11 & $\mathrm{~N}$-benzyl-pyrazinecarboxamide $\mathbf{1 f}$ & 1.81 & 0.40 \\
\hline \multirow[t]{2}{*}{12} & $\begin{array}{l}\text { N-benzyl-N-Boc-pyrazine- } \\
\text { carboxamide } 2 f\end{array}$ & 1.41 & \\
\hline & pyrazinecarboxamide & 1.75 & \\
\hline \multirow{3}{*}{$\begin{array}{l}13 \\
14\end{array}$} & $\mathrm{~N}$-benzyl-2-quinolinecarboxamide $\mathbf{1 g}$ & 1.74 & 0.43 \\
\hline & $\begin{array}{l}\mathrm{N} \text {-benzyl-N-Boc-2-quinoline- } \\
\text { carboxamide } \mathbf{2 q}\end{array}$ & 1.31 & \\
\hline & 2-quinol inecarboxamide & 1.81 & \\
\hline
\end{tabular}

${ }^{a}$ All compounds 1 and 2 were characterized by ${ }^{1} \mathrm{H}$ and ${ }^{13} \mathrm{C}$ NMR and FT-IR spectroscopy. All novel substances also gave satisfactory elemental analyses (C, H, N all within $0.3 \%$ of theoretical values). ${ }^{b}$ Versus SCE; cathode, vitreous carbon; solvent, DMF; supporting electrolyte, $\mathrm{Bu}_{4} \mathrm{NBF}_{4}$ $0.1 \mathrm{M}$; substrate concentration, $\sim 0.005 \mathrm{M}$

of these carboxamides as was previously noticed in several cases for sulfonamides. ${ }^{6}$ Numerically these shifts are about half the size of the decrease in reduction potential on going from benzene to naphthalene..$^{\mathrm{a}, \mathrm{b}}$ Moreover, by introduction of $N$-Boc moieties on these naphthalenecarboxamides, the peak potentials are further shifted by about $0.3 \mathrm{~V}$ to less negative values.

Previously a few 2- and 3-pyridinecarboxamides have been prepared and studied with respect to their cleavage. ${ }^{7}$ 4-Pyridinemethyl esters ${ }^{8 \mathrm{a}}$ and carbamates ${ }^{8 \mathrm{~b}, \mathrm{c}}$ are stable to a variety of experimental conditions and can be cleaved electrochemically ${ }^{8 \mathrm{a}, \mathrm{c}}$ and by zinc dust reduction. ${ }^{8 \mathrm{c}}$ The quoted work induced us to include pyridinecarboxamides and the corresponding $N$-Boc derivatives in this study. Entries 5, 7, and 9 show that the activation potentials for the three isomeric pyridinecarboxamides $\mathbf{1 c}-\mathbf{e}$ are of about the same size as for $\mathbf{1 a}$ and $\mathbf{1 b}$ with positions 2 and 4 in the pyridine rings favorously activated for reductive attack. Introduction of Boc on the nitrogens (entries 6, 8 and 10) gives rise to a further shift in the same direction and of about the same size as observed for the corresponding naphthalene derivatives.

(6) Nyasse, B.; Grehn, L.; Maia, H. L. S.; Monteiro, L. S.; Ragnarsson, U. J. Org. Chem. 1999, 64, 7135.

(7) (a) Auzeil, N.; Dutruc-Rosset, G.; Largeron, M. Tetrahedron Lett. 1997, 38, 2283. (b) Ushida, S. Chem. Lett. 1989, 59.

(8) (a) Camble, R.; Garner, R.; Young, G. T. J. Chem. Soc. C 1969, 1911. (b) Macrae, R.; Young, G. T. J. Chem. Soc., Chem. Commun. 1974, 446. (c) Veber, D. F.; Paleveda, W. J. Jr.; Lee, Y. C.; Hirschmann, R. J. Org. Chem. 1977, 42, 3286.
These shifts are significant as differences in activation potentials of $0.3-0.6 \mathrm{~V}$ for similar compounds could be exploited for selective cleavage by electrolysis. ${ }^{9}$

The significance of the data in Table 1 with respect to reductive amide cleavage was first challenged by experiments with activated Al. ${ }^{10}$ Compounds $\mathbf{2 c}, \mathbf{2 d}$, and $\mathbf{2 e}$ thereby furnished 3 in $89 \%, 74-85 \%$, and $90 \%$ yields, respectively:

$$
\mathbf{2} \stackrel{\mathrm{Al}}{\longrightarrow} \mathrm{HNBoc}-\mathrm{Bn}(\mathbf{3})
$$

This reagent ${ }^{11}$ is known to reductively cleave sulfonamides ${ }^{6}$ with activation potentials down to -1.7 to $-1.8 \mathrm{~V}$, and it obviously also reacts with carboxamides in a similar fashion. It also cleaved $\mathbf{2 f}$ and $\mathbf{2 g}$ (49\% and 95\%).

Pyrazine and quinoline are known to undergo dearomatization at even less negative potential than pyridine, ${ }^{5 \mathrm{c}, \mathrm{d}}$ and this is reflected in the $\mathrm{CV}$ data for $\mathbf{1 f} / \mathbf{2 f}$ and $\mathbf{1 g} / \mathbf{2 g}$. As shown in entries 11 and 13, the activation potentials of $\mathbf{1 f}$ and $\mathbf{1 g}$ are already comparable with the best Boc-derivatives derived from naphthalene and pyridine above. Interestingly, the shift induced by introduction of Boc on their amide nitrogens does not show any indication of decrease, and compounds $2 \mathbf{f}$ and $\mathbf{2 g}$ exhibit activation potentials of only -1.41 and $-1.31 \mathrm{~V}$ vs SCE, respectively, i.e., nearly $0.5 \mathrm{~V}$ above the previous Boc-derivatives. They could also be cleaved by preparative electrolysis experiments, ${ }^{12}$ furnishing 3 in $66 \%$ and $96 \%$ yields.

Many years ago, Weygand and Frauendorfer demonstrated that $N$-trifluoroacetyl and trichloroacetyl groups could be efficiently cleaved by reduction under exceedingly mild conditions with $\mathrm{NaBH}_{4}{ }^{13 a}$ More recently Ganem et al. developed a preparatively useful cleavage method for phthalimides based on partial reduction with this agent. ${ }^{13 \mathrm{~b}}$ Having established the facile reduction of selected compounds 2 by electrolysis and activated aluminum, a few experiments with $\mathrm{NaBH}_{4}$ in absolute ethanol at room temperature were undertaken with isolation of $\mathbf{3}$ from $\mathbf{2 c}$ and 2f in $97-98 \%$ and from $\mathbf{2 a}$ in $91 \%$ yields, in the last case after column chromatography, which also furnished pure 1-naphthylmethanol $(90 \%)$. The rate of the reaction with

(9) Grehn, L.; Maia, H. L. S.; Monteiro, L. S.; Montenegro, M. I.; Ragnarsson, U. J. Chem. Res. 1991, (S) 144; (M) 1501.

(10) The cleavage experiments with activated Al were performed with $1 \mathrm{mmol}$ of 2 and $10 \mathrm{mmol}$ of reducing agent, essentially as described in the example given in ref 6 . Occasionally $\mathbf{2 d}$ required additional $\mathrm{Al}$ to go to completion. As an example, 2c (312 mg, $1.00 \mathrm{mmol})$ was treated in moist $\mathrm{Et}_{2} \mathrm{O}$ under stirring with $10 \mathrm{mmol}$ reagent overnight, whereupon TLC indicated that all $\mathbf{2 c}$ had been consumed. After filtration of the solid material and evaporation of the combined filtrate and washings, a brown oil was obtained. TLC and ${ }^{1} \mathrm{H}$ NMR indicated that it consisted of essentially pure 3. Only trace signals beyond $7.5 \mathrm{ppm}$, indicating pyridine derivates originating from the picolyl residue, could be detected. The yield of crude 3 was $184 \mathrm{mg}(89 \%)$

(11) Hudlický, M. Reductions in Organic Chemistry, 2nd ed.; ACS Monograph 188; American Chemical Society: Washington, DC, 1996; p 35 .

(12) The preparative electrolysis experiments with $\mathbf{2 f}$ and $\mathbf{2 g}$ were performed as described in the example under Controlled Potential Electrolysis in ref 6 (at a scale of ca. $0.7 \mathrm{mmol}$ and the potentials -1.46 and $-1.36 \mathrm{~V}$, respectively), and $\mathbf{3}$ was identified by $\mathrm{mp}$ and spectroscopic comparison with an authentic sample.

(13) (a) Weygand, F.; Frauendorfer, E. Chem. Ber. 1970, 103, 2437. (b) Osby, J. O.; Martin, M. G.; Ganem, B. Tetrahedron Lett. 1984, 25, 2093 and references therein. 
$\mathrm{NaBH}_{4}$ varies from substrate to substrate and is very high for $\mathbf{2 f}$, for which the starting material is consumed in $10-$ $15 \mathrm{~min}$, whereas for $\mathbf{2 c}$ and even $\mathbf{2 g}$ reaction times of $2-4$ $\mathrm{h}$ are required, using 2-2.5 mol of reagent. Compound 2a reacts even more slowly.

In summary, as a consequence of extended conjugation a few heteroaromatic acylcarbamates derived from easily reduced heterocycles have been shown to undergo regioselective acyl-nitrogen cleavage under exceedingly mild reductive conditions. Selected derivatives have been cleaved by activated aluminum, controlled potential electrolysis, and $\mathrm{NaBH}_{4}$. A deeper understanding of the factors promoting enhanced reductive cleavage is expected to lead to robust protecting groups with high versatility.

Acknowledgment. U.R. thanks NFR and Magnus Bergvalls Stiftelse for generous support and RSC for a journals grant for international authors. L.G. acknowledges a grant from TFR, and H.L.S.M. and L.S.M. thank the Foundation for Science and Technology (Portugal) for financial support to the Institute of Biotechnology and Fine Chemistry (University of Minho).

OL010072A 